\title{
Validação das Equações do NRC (2001) para Predição do Valor Energético de Alimentos nas Condições Brasileiras ${ }^{1}$
}

\author{
Marcos Antonio Lana Costa ${ }^{2}$, Sebastião de Campos Valadares Filho ${ }^{3}$, Rilene Ferreira Diniz \\ Valadares ${ }^{4}$, Mário Fonseca Paulino ${ }^{3}$, Paulo Roberto Cecon ${ }^{5}$, Pedro Veiga Rodrigues Paulino ${ }^{6}$, \\ Mário Luiz Chizzotti ${ }^{6}$, Mônica Lopes Paixão6
}

\begin{abstract}
RESUMO - O estudo foi conduzido para estimar os valores energéticos (NDT) de vários alimentos, concentrados e volumosos e validar as equações propostas pelo NRC (2001) por meio da comparação dos valores estimados por estas equações, com os observados, obtidos a partir da coleta total de fezes. Foram avaliados cinco alimentos concentrados (farelo de trigo, farelo de soja, fubá de milho, grão de soja e caroço de algodão) e cinco volumosos (feno de capim-braquiária, silagem de milho, silagem pré-seca de capim-tifton, silagem de capim-elefante e capim-elefante) utilizando-se 20 novilhos mestiços HolandêsxZebu. O procedimento de validação das variáveis avaliadas foi realizado por intermédio do ajuste do modelo de regressão linear simples dos valores preditos e observados. Os valores de NDT dos alimentos concentrados e volumosos observados e preditos pelas equações do NRC (2001) foram similares (P>0,05). Conclui-se que as equações do NRC (2001) foram adequadas para estimar o valor energético dos alimentos nas condições brasileiras.
\end{abstract}

Palavras-chave: concentrados, equações NRC (2001), NDT, valor energético, volumosos

\section{Validation of NRC (2001) Equations for Estimation of Energy Value of Feeds in Brazilian Conditions}

\begin{abstract}
This research was developed to estimate the energy values (TDN) of feeds, concentrate and roughage, through equations proposed by NRC (2001) and validate from the comparison among TDN values estimated by these equations and those observed in the total collection feces. Five concentrate feeds (wheat bran, soybean meal, corn ground, whole soybean and whole cotton seed) an five roughage feeds (brachiaria hay, corn silage, tifton haylage, elephant grass silage and elephantgrass) were evaluated by using 20 crossbred Holstein x Zebu steers. The procedure to validate the variables evaluated was done by adjusting models of simple linear regression using predicted and observed values. The observed and predicted value of TDN values for roughage and concentrate feeds were similar ( $\mathrm{P}>0,05)$. It was concluded that the equations proposed by NRC (2001) were efficient to estimate the TDN values of feeds under brazilian conditions.
\end{abstract}

Key Words: concentrate, energy value, NRC (2001) equation, roughage, TDN

\section{Introdução}

Além da composição bromatológica dos alimentos, é importante o conhecimento da capacidade de utilização dos nutrientes pelo animal, o que pode ser obtido com estudos de digestão. Van Soest (1994) define digestão como o processo de conversão de macromoléculas da dieta em compostos mais simples, que podem ser absorvidos no trato gastrointestinal dos animais.

A digestibilidade do alimento é a capacidade do animal em utilizar, em maior ou menor escala, seus nutrientes. Neste aspecto, alimentos de maior digestibilidade podem ser considerados de maior valor nutritivo. Medidas de digestibilidade têm contribuído significativamente para o desenvolvimento de sistemas para descrever o valor nutritivo dos alimentos (Van Soest, 1994).

O efeito associativo ou a interação entre diferentes componentes pode ser um problema na determinação da digestibilidade. Efeitos associativos entre alimentos, em virtude da incorporação de um ou mais ingredientes na dieta, poderão produzir mudanças na digestão e no metabolismo dos nutrientes. Segundo Teixeira (1997), citado por Rocha Jr. (2002), a técnica de determinação da digestibilidade por sistema de

\footnotetext{
1 Parte da tese de Mestrado do primeiro autor, parcialmente financiada pela FAPEMIG.

2 Zootecnista, M.Sc. E.mail: mzootec@yahoo.com.br

3 Professor do DZO/UFV. E.mail: scvfilho@ufv.br

4 Professora DVT/UFV.

${ }^{5}$ Professor DPI/UFV.

${ }^{6}$ Estudante do curso de Doutorado, DZO/UFV.
} 
equações, pode ser utilizada quando o alimento a ser avaliado não preenche o volume fisiológico do trato gastrintestinal do animal. Especialmente para ruminantes, esta técnica se aplica à avaliação de alimentos concentrados e, em trabalhos com duas ou mais rações, pode-se amenizar os erros decorrentes do efeito associativo entre os ingredientes.

Rocha Júnior et al. (2003a) realizaram ensaio de digestibilidade com ovinos, utilizando três ingredientes concentrados (fubá de milho, grão de sorgo moído e farelo de trigo), de modo que cada um deles foi combinado ao mesmo tipo de feno nas proporções de 0,9 feno: 0,1 concentrado e 0,7 feno: 0,3 concentrado, com o objetivo de avaliar a influência dos alimentos concentrados sobre a digestibilidade do feno. A digestibilidade de cada alimento foi obtida por diferença, empregando-se sistema de equações. Não houve interferência dos alimentos concentrados sobre a digestibilidade do feno. Os autores, determinando o valor energético de vários alimentos concentrados e volumosos, concluíram que a utilização de sistemas de equações para determinação da digestibilidade dos alimentos mostrou-se eficiente.

Estimativas acuradas da disponibilidade da energia contida nos alimentos são necessárias para se formular dietas e avaliar os valores nutricional e econômico dos alimentos. Segundo Weiss (1993), apesar de a quantidade total de energia contida no alimento ser facilmente medida pela combustão do alimento na bomba calorimétrica, a variabilidade na digestibilidade e metabolismo dos alimentos impede o uso da energia bruta na formulação de dietas ou comparação de alimentos. Entre as fontes de variação, estariam incluídos o animal, o alimento e os fatores ligados à alimentação.

De acordo com o NRC (1989), o sistema de energia líquida (EL) fornece valores de disponibilidade de energia muito mais precisos que os nutrientes digestíveis totais (NDT), mas este sistema ainda permanece porque os valores de EL são de difícil determinação e também porque há grande quantidade de informações disponíveis sobre NDT. Segundo Valadares Filho (2000), considerando que grande parte da avaliação energética dos alimentos se baseia no NDT e que os cálculos de EL são estimados a partir do NDT ou da EM, oriunda também do NDT, sugerese que o NDT possa ser considerado, no momento, como uma unidade possível de ser utilizada para formulação de rações.

O NRC (2001) propôs um método somativo para estimativa do NDT dos alimentos que diferiu substan- cialmente das versões anteriores. O NDT do alimento, com o consumo de matéria seca em nível de

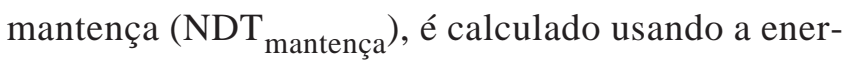
gia produzida pelas frações químicas do alimento (carboidratos fibrosos, carboidratos não-fibrosos, lipídeos e proteína bruta), medidas ou calculadas por meio de análise de laboratório, e de suas digestibilidades verdadeira (valores conhecidos ou calculados), a partir de equações. Os dados de composição do alimento requeridos para uma descrição precisa do conteúdo de energia incluem: proteína bruta $(\mathrm{PB})$, extrato etéreo (EE), fibra em detergente neutro (FDN), carboidratos não-fibrosos (CNF), lignina (L), proteína insolúvel em detergente ácido (PIDA) e proteína insolúvel em detergente neutro (PIDN).

Segundo o NRC (2001), em virtude de os nutrientes possuírem diferentes calores de combustão, o valor de energia bruta do NDT não seria constante entre os alimentos. Portanto, propôs-se o cálculo da energia digestível de mantença ( $\left.\mathrm{ED}_{\text {mantença }}\right)$, a partir da multiplicação das concentrações de nutrientes digestíveis estimados pelas equações pelos respectivos calores de combustão, conforme a equação abaixo:

$\mathrm{ED}_{\text {mantença }}(\mathrm{Mcal} / \mathrm{kg})=((\mathrm{PBD} / 100) \times 5,6+(\mathrm{AGD} / 100)$ x 9,4 + (CNFD/100) x 4,2 + (FDND/100) x 4,2) - 0,3

Como a ED se baseia na digestibilidade aparente e as equações para estimativas das frações digestivas (PBD, AGD, CNFD e FDND) referem-se à digestibilidade verdadeira, foi sugerida a subtração do valor 0,3 como correção para energia fecal metabólica.

O NRC (2001) acrescenta ainda que a digestibilidade dos alimentos pode ser reduzida em função do aumento no consumo. Desta forma, propôs o cálculo de um fator de desconto que deveria ser aplicado na $\mathrm{ED}_{\text {mantença }}$ obtida por essa fórmula, corrigindo-a para o efeito do consumo sobre a digestibilidade, conseqüentemente sobre o valor energético dos alimentos, obtendo a $\mathrm{ED}_{\text {produtiva }} \mathrm{O}$ valor de EM seria, então, calculado pelas equações, a partir da $\mathrm{ED}_{\text {produtiva }}$ e a EL, a partir da EM.

A equação a seguir foi utilizada para calcular o fator de desconto. De acordo com a equação, o declínio em digestibilidade depende do consumo de matéria seca acima da mantença e da digestibilidade da dieta na mantença. Segundo o NRC (2001), abaixo de $60 \%$ de $\mathrm{NDT}_{\text {mantença }}$, este desconto pode ser negligencia- 
do. O nível de consumo de matéria seca da dieta proposta, além do nível de mantença, deve ser conhecido para se calcular o fator de desconto (FC), que reflete o decréscimo em digestibilidade resultante do aumento na taxa de passagem, quando os animais estão consumindo mais alimento. Dietas com alta digestibilidade apresentam queda na digestibilidade, quando comparadas a dietas de baixa digestibilidade. É assumido que a redução na digestibilidade com o aumento de consumo se origina da redução na extensão de fermentação dos carboidratos (fibrosos, principalmente) no rúmen (Wattiaux, 2001).

$\mathrm{FC}=\mathrm{NDT}-((0,18 \mathrm{NDT}-10,3) \mathrm{x}$ nível de ingestão)/NDT, em que NDT é expresso em percentagem da MS

Vale ressaltar que o valor de NDT refere-se à dieta total e não aos alimentos individualmente, enquanto o nível de ingestão corresponde ao incremento de consumo acima da mantença (Ex.: para um animal consumindo três vezes o valor de mantença, utilizase o valor 2). Multiplicando-se o FC pelo teor de ED, obtém-se a $\mathrm{ED}_{\text {produtiva }}$, utilizando-se, posteriomente, equações para estimar EM e EL.

Considerando que o NRC (2001) recomendou novas metodologias para avaliar o valor energético dos alimentos de acordo com sua composição químico-bromatológica, e que as equações propostas deverão ser validadas para se estimar o valor energético dos alimentos no Brasil, foi conduzido experimento com o objetivo de determinar o valor energético de alimentos, volumosos e concentrados, pelo método tradicional de coleta total de fezes e comparar os valores obtidos com aqueles preditos pelo NRC (2001).

\section{Material e Métodos}

O trabalho foi conduzido no Laboratório de Animais do Departamento de Zootecnia da Universidade Federal de Viçosa, no mês de agosto de 2001.

Foram determinados os teores de NDT dos seguintes alimentos volumosos: feno de capimbraquiária, silagem de milho, silagem de capim-elefante, silagem pré-seca de capim-tifton e capim-elefante; e dos alimentos concentrados: farelo de trigo, farelo de soja, grão de soja, milho e caroço de algodão, utilizando 20 bovinos HolandêsxZebu em fase de crescimento, com aproximadamente $250 \mathrm{~kg}$ de peso vivo, em delineamento inteiramente casualizado.

Inicialmente, todos os animais foram pesados, identificados e tratados contra ecto e endoparasitas. Após a primeira pesagem, efetuou-se a distribuição dos animais, de modo que, para cada tratamento, foram utilizados animais com pesos médios semelhantes.

Os animais foram mantidos em regime de confinamento, alojados em baias individuais cobertas, com piso de concreto revestido de borracha, dotadas de comedouros de alvenaria e de bebedouros individuais.

Volumosos e concentrados foram combinados em dois níveis distintos, com quatro repetições para cada. Os mesmos quatro animais foram utilizados nos dois níveis do ingrediente concentrado ou volumoso, em dois períodos consecutivos, de modo que, no segundo período, os animais foram alimentados com dietas contendo o maior nível de concentrado. Cada período teve duração de 13 dias (10 dias para adaptação e três dias para coleta total de fezes).

Os alimentos foram combinados da seguinte maneira: feno de capim-braquiária com 10 e $35 \%$ de farelo de trigo; silagem de milho com 6 e $12 \%$ de farelo de soja; silagem de capim-elefante com 7,5 e $15 \%$ de grão de soja; silagem pré-seca de capim-tifton com 10 e $30 \%$ de milho; capim-elefante com 5 e $15 \%$ de caroço de algodão (Tabela 1). Utilizou-se a mistura uréia/sulfato de amônio (9:1) para que as rações contendo as duas proporções de cada alimento concentrado se mantivessem isoprotéicas nos dois diferentes períodos experimentais.

Os coeficientes de digestibilidade da proteína bruta (DPB), do extrato etéreo (DEE), da fibra em detergente neutro (DFDN) e dos carboidratos nãofibrosos (DCNF) de cada alimento foram determinados a partir dos coeficientes médios de digestibilidade das dietas específicas de cada tratamento, pelos sistemas de equações, de modo que a digestibilidade de cada ingrediente foi obtida por diferença, conforme o seguinte exemplo:

0,9 Feno $+0,1$ Farelo de trigo $=$ DPB

0,65 Feno $+0,35$ Farelo de trigo $=$ DPB

As dietas foram fornecidas à vontade, de modo a propiciar $10 \%$ de sobras. Realizou-se a coleta total de fezes dos animais em cada período experimental, por um período de 72 horas, registrando-se a quantidade total excretada por animal. Durante a pesagem das fezes, foram retiradas alíquotas de, aproximadamente, $5 \%$, para posterior confecção das amostras compostas de cada animal. Durante o período de coleta de 
Tabela 1 - Ingredientes e relação concentrado:volumoso nos diferentes tratamentos experimentais Table 1 - Ingredients and relation between concentrate:roughage in the different treatments

\begin{tabular}{|c|c|c|}
\hline $\begin{array}{l}\text { Tratamentos } \\
\text { Treatments }\end{array}$ & $\begin{array}{c}\mathrm{V}: \mathrm{C}: \mathrm{U}^{*} \\
R: C: U^{*} \\
\text { Período } 1 \\
\text { Period } 1 \\
\end{array}$ & $\begin{array}{c}\text { V:C:U* } \\
R: C: U^{*} \\
\text { Período } 2 \\
\text { Period } 2 \\
\end{array}$ \\
\hline $\begin{array}{l}\text { Feno de braquiária + Farelo trigo + Uréia } \\
\text { Braquiária hay }+ \text { Wheat bran }+ \text { Urea }\end{array}$ & $89: 10: 1$ & $65: 35$ \\
\hline $\begin{array}{l}\text { Silagem de milho + Farelo de soja + Uréia } \\
\text { Corn silage + Soybean meal + Urea }\end{array}$ & $93: 6: 1$ & $88: 12$ \\
\hline $\begin{array}{l}\text { Silagem pré-seca de tifton }+ \text { Fubá de milho + Uréia } \\
\text { Tifton haylage }+ \text { Corn grain ground }+ \text { Urea }\end{array}$ & $90: 10$ & $69,5: 30: 0,5$ \\
\hline $\begin{array}{l}\text { Sil. de capim-elefante + grão de soja + Uréia } \\
\text { Elephantgrass silage }+ \text { Whole soybean + Urea }\end{array}$ & $91,5: 7,5: 1$ & $85: 15$ \\
\hline $\begin{array}{l}\text { Capim-elefante + Caroço de algodão + Uréia } \\
\text { Elephantgrass }+ \text { Whole cotton seed }+ \text { Urea }\end{array}$ & $93,9: 5: 1,1$ & $84,5: 15: 0,5$ \\
\hline
\end{tabular}

fezes, foram registradas as quantidades de alimento consumido diariamente, coletando-se amostras dos volumosos e concentrados oferecidos por tratamento e das sobras por animal.

As amostras de alimentos, sobras e fezes foram devidamente armazenadas em freezer. Posteriormente, foram pré-secas em estufa de ventilação forçada, a $65^{\circ} \mathrm{C}$ por 72 horas, moídas em peneira de malha de $1 \mathrm{~mm}$ e submetidas às análises laboratoriais.

A composição química e bromatológica dos alimentos utilizados pode ser observada na Tabela 2. As determinações de matéria seca (MS), matéria orgânica (MO), nitrogênio total, extrato etéreo (EE), fibra em detergente neutro (FDN) dos alimentos, das sobras e das fezes e as estimativas de fibra em detergente ácido (FDA) e de lignina dos alimentos foram realizadas conforme Silva (1990), sendo a proteína bruta (PB) obtida pelo produto entre o teor de nitrogênio total e o fator 6,25 . Os teores de compostos nitrogenados insolúveis em detergente neutro (NIDN) e em detergente ácido (NIDA) dos alimentos foram estimados nos resíduos obtidos após a extração das amostras nos detergentes neutro e ácido, respectivamente (Van Soest et al., 1991), por intermédio do procedimento de Kjeldahl, com a FDN dos alimentos corrigida para os níveis de cinzas e proteína, obtendose a fibra em detergente neutro isenta de cinzas e proteínas (FDNcp).

Os carboidrados não-fibrosos (CNF) foram calculados de acordo com Weiss (1999), como: CNF $(\%)=100-(\% \mathrm{FDNcp}+\% \mathrm{~PB}+\% \mathrm{EE}+\%$ cinzas $)$.
O teor de nutrientes digestíveis totais (NDT) observado foi obtido a partir da equação somativa: $\mathrm{NDT}=\mathrm{PBD}+2,25 \times \mathrm{EED}+\mathrm{FDNcpD}+\mathrm{CNFD}$, em que PBD, EED, FDNcp e CNFD significam, respectivamente, proteína bruta digestível, extrato etéreo digestível, fibra em detergente neutro (isenta de cinzas e proteína) digestível e carboidratos não-fibrosos digestíveis.

A partir da composição dos alimentos avaliados, foram estimados os valores de NDT mantença, conforme equações do NRC (2001), que estima os teores de proteína bruta digestível(PBD), ácidos graxos digestíveis (AGD), fibra em detergente neutro isenta de proteínas digestível (FDNp) e carboidratos não-fibrosos digestíveis (CNFD), conforme descrito a seguir:

- PBD para alimentos volumosos $=\mathrm{PB} \times \operatorname{Exp}(-1,2$ $\mathrm{x}(\mathrm{PIDA} / \mathrm{PB}))$; em que PIDA = proteína insolúvel em detergente ácido;

- $\mathrm{PBD}$ para alimentos concentrados $=\mathrm{PB} \times[1-(0,4$ $\mathrm{x}$ PIDA/PB)];

- $\mathrm{AGD}=(\mathrm{EE}-1) \times 100$;

- $\mathrm{CNFD}=0,98 \times \mathrm{CNF} \times \mathrm{FAP}$; em que FAP $=$ fator de ajuste para processamento físico, de acordo com os valores apresentados na Tabela 3;

- $\mathrm{FDNpD}=0,75(\mathrm{FDNp}-\mathrm{L}) \times\left[1-(\mathrm{L} / \mathrm{FDNp})^{0,667}\right]$; em que $\mathrm{L}=$ Lignina.

Para estimar os nutrientes digestíveis totais em nível de mantença (NDT mantença $_{\text {) }}$ de acordo com o NRC (2001), a equação utilizada foi: $\mathrm{NDT}_{\text {mantença }}=$ $\mathrm{PBD}+2,25 \mathrm{AGD}+\mathrm{FDNpD}+\mathrm{CNFD}$ - 7; em que o valor 7 se refere ao NDT fecal metabólico. 
Tabela 2 - Composição química e bromatológica dos alimentos avaliados, expressa na base da matéria seca

Table 2 - Proximal analyses of the feeds evaluated, on dry matter basis

\begin{tabular}{|c|c|c|c|c|c|c|c|c|c|c|}
\hline $\begin{array}{l}\text { Alimentos } \\
\text { Feeds }\end{array}$ & $\begin{array}{l}\text { MO } \\
O M\end{array}$ & $\begin{array}{l}\mathrm{PB} \\
C P\end{array}$ & $\begin{array}{l}\mathrm{NIDN}^{1} \\
N D I N^{1}\end{array}$ & $\begin{array}{l}\mathrm{NIDA}^{1} \\
A D I N^{1}\end{array}$ & $\begin{array}{l}\mathrm{EE} \\
E E\end{array}$ & $\begin{array}{l}\mathrm{FDN} \\
N D F\end{array}$ & $\begin{array}{l}\text { FDNcp } \\
\text { NDFap }\end{array}$ & $\begin{array}{l}\mathrm{CNF} \\
N F C\end{array}$ & $\begin{array}{l}\mathrm{FDA} \\
A D F\end{array}$ & $\begin{array}{l}\text { Lignina } \\
\text { Lignin }\end{array}$ \\
\hline $\begin{array}{l}\text { Farelo de trigo } \\
\text { Wheat bran }\end{array}$ & 94,9 & 15,9 & 7,2 & 2,7 & 3,9 & 36,1 & 34,7 & 40,4 & 13,7 & 3,0 \\
\hline $\begin{array}{l}\text { Farelo de soja } \\
\text { Soybean meal }\end{array}$ & 93,9 & 50,9 & 4,7 & 3,2 & 1,7 & 14,3 & 11,6 & 29,7 & 9,4 & 1,5 \\
\hline $\begin{array}{l}\text { Grão de soja } \\
\text { Whole soybean }\end{array}$ & 95,3 & 40,2 & 15,0 & 6,5 & 19,5 & 21,3 & 15,1 & 20,4 & 11,9 & 2,1 \\
\hline $\begin{array}{l}\text { Fubá de milho } \\
\text { Corn ground }\end{array}$ & 98,9 & 8,31 & 15,2 & 6,95 & 4,0 & 15,3 & 13,6 & 73,0 & 2,9 & 0,2 \\
\hline $\begin{array}{l}\text { Caroço de algodão } \\
\text { Whole cotton seed }\end{array}$ & 96,5 & 18,9 & 11,5 & 9,59 & 21,2 & 48,2 & 45,4 & 10,9 & 37,4 & 3,0 \\
\hline $\begin{array}{l}\text { Feno de braquiária } \\
\text { Braquiária hay }\end{array}$ & 94,4 & 5,4 & 37,8 & 8,80 & 1,4 & 78,9 & 75,7 & 11,8 & 39,4 & 6,6 \\
\hline $\begin{array}{l}\text { Silagem de milho } \\
\text { Corn silage }\end{array}$ & 95,3 & 5,6 & 15,0 & 5,76 & 2,9 & 53,0 & 51,6 & 34,2 & 26,5 & 3,9 \\
\hline $\begin{array}{l}\text { Sil. capim-elefante } \\
\text { Elephantgrass silage }\end{array}$ & 94,5 & 4,2 & 25,2 & 17,85 & 1,0 & 78,6 & 74,2 & 11,2 & 50,7 & 10,2 \\
\hline $\begin{array}{l}\text { Sil. pré-sec. tifton } \\
\text { Tifton haylage }\end{array}$ & 92,2 & 15,3 & 26,8 & 5,13 & 1,5 & 70,4 & 64,4 & 11,1 & 33,9 & 5,2 \\
\hline $\begin{array}{l}\text { Capim-elefante } \\
\text { Elephantgrass }\end{array}$ & 92,4 & 4,8 & 18,2 & 9,77 & 2,3 & 75,2 & 73,1 & 12,2 & 44,9 & 7,4 \\
\hline
\end{tabular}

$1 \%$ do nitrogênio total; MO - matéria orgânica; PB - proteína bruta; NIDN - compostos nitrogenados insolúveis em detergente neutro; NIDA - compostos nitrogenados insolúveis em detergente ácido; EE - extrato etéreo; FDN - fibra em detergente neutro; FDNcp - fibra em detergente neutro corrigida para cinzas e proteínas; CNF - carboidratos não-fibrosos; FDA - fibra em detergente ácido.

$1 \%$ of total nitrogen; OM - organic matter; CP - crude protein; NDIN - neutral detergent insoluble nitrogen; $A D I N$ - acid detergent insoluble nitrogen; EE - ether extract, NDF neutral detergent fiber; NDFap - neutral detergent fiber adjusted for ash and protein; NFC - nonfiber carbohydrate; ADF - acid detergent fiber.

Tabela 3 - Fatores de ajuste para o processamento físico (FAP)

Table 3 - Processing adjustment factors (PAF)

\begin{tabular}{lc}
\hline Alimentos & FAP \\
Feeds & $P A F$ \\
\hline Farelo de cereais & 1,04 \\
$\begin{array}{l}\text { Cereal meal } \\
\text { Milho grão moído } \\
\text { Corn grain ground }\end{array}$ & 1,00 \\
$\begin{array}{l}\text { Silagem de milho } \\
\text { Corn silage }\end{array}$ & \\
$\begin{array}{l}\text { Sorgo grão laminado } \\
\text { Sorghum grain, dry rolled } \\
\text { Todos os outros alimentos } \\
\text { All other feeds }\end{array}$ & 0,94 \\
Font NRC 2001$) .0,92$ \\
\end{tabular}

Fonte: NRC (2001).

Source: $N R C$ (2001). 
A validação das equações do NRC (2001) para estimativa do valor energético dos alimentos (NDT) foi avaliada a partir da comparação dos valores observados in vivo (coleta total de fezes), pelo método de coleta total de fezes, com os valores estimados por meio das equações. O procedimento de validação das equações do NRC (2001) foi feito por intermédio do ajuste de modelo de regressão linear simples dos valores preditos sobre os observados, de acordo com o seguinte modelo: $Y_{i}=\beta_{1} x_{i}$ $+\mathrm{e}_{\mathrm{i}}$, em que $\mathrm{Y}_{\mathrm{i}}=$ valor de NDT predito; $\mathrm{b}_{1}=$ coeficiente de inclinação da reta; $x_{i}=$ NDT observado e $e_{i}=$ erro aleatório, associado a cada observação.

A estimativa do parâmetro $b_{1}$ da equação de regressão foi testada sobre as seguintes hipóteses:

$$
\begin{aligned}
& \mathrm{H}_{0}: \beta_{1}=1 \\
& \mathrm{H}_{1}: \beta_{1} \neq 1
\end{aligned}
$$

Quando da não-rejeição da hipótese de nulidade, os valores preditos e observados são similares, enquanto, no caso da rejeição da hipótese de nulidade, verificou-se a presença do vício global de estimação (VGE). O vício global de estimação é estimado como: $\mathrm{VGE}=\left(\beta_{1}-1\right) \times 100$, em que $\beta_{1}=$ estimativa do coeficiente angular da equação de regressão sem intercepto e $1=$ valor paramétrico para o coeficiente angular sob a pressuposição de $\mathrm{H}_{0}$ ser verdadeira. Para todos os procedimentos estatísticos descritos, adotou-se $\alpha=0,05$.

\section{Resultados e Discussão}

Na Tabela 4, são apresentados os valores de NDT observados no experimento e os valores preditos pelo NRC (2001). Os alimentos foram agrupados em volumosos, concentrados e conjunto de alimentos (volumosos+concentrados) para os procedimentos estatísticos adotados.

$\mathrm{Na}$ Tabela 5, estão presentes as estimativas do parâmetro ${ }_{1}$, bem como os coeficientes de determinação $\left(\mathrm{r}^{2}\right)$ das equações de regressão obtidas a partir das comparação dos valores de NDT observados com os preditos pelo NRC (2001). O coeficiente de inclinação da reta ${ }_{1}$ não diferiu estatisticamente de 1 para todas as variáveis analisadas, denotando que os valores de NDT observados foram similares aos estimados pelas equações do NRC (2001), comprovando que as equações propostas pelo NRC foram eficientes para estimar o valor energético dos alimentos nas condições brasileiras.

Rocha Jr. et al. (2003b), ao avaliarem a eficácia das equações propostas pelo NRC (2001) para avaliação energética de alimentos, compararam os valores preditos pelas equações e observados em um experimento com ovinos à uma coletânea de valores de NDT obtidos na literatura nacional a partir de experimentos in vivo e concluíram, da mesma forma,

Tabela 4 - Valores de NDT (\%) observados no experimento e preditos pelas equações do NRC (2001)

Table 4 - TDN values (\%) observed and predicted by the NRC (2001) equations

\begin{tabular}{lcc}
\hline $\begin{array}{l}\text { Alimento } \\
\text { Feed }\end{array}$ & $\begin{array}{c}\text { NDT observado } \\
\text { Observed TDN }\end{array}$ & $\begin{array}{c}\text { NDT predito } \\
\text { Predicted TDN }\end{array}$ \\
\hline $\begin{array}{l}\text { Feno de braquiária } \\
\text { Brachiaria hay }\end{array}$ & 55,2 & 51,7 \\
$\begin{array}{l}\text { Silagem de milho } \\
\text { Corn silage }\end{array}$ & 60,2 & 62,5 \\
$\begin{array}{l}\text { Silagem de capim-elefante } \\
\text { Elephantgrass silage }\end{array}$ & 44,6 & 42,4 \\
$\begin{array}{l}\text { Silagem pré-seca de tifton } \\
\text { Tifton haylage }\end{array}$ & 62,4 & 59,4 \\
$\begin{array}{l}\text { Capim-elefante } \\
\text { Elephantgrass }\end{array}$ & 46,7 & 48,9 \\
$\begin{array}{l}\text { Farelo de trigo } \\
\text { Wheat bran }\end{array}$ & 72,0 & 71,9 \\
$\begin{array}{l}\text { Farelo de soja } \\
\text { Soybean meal } \\
\text { Grão de soja }\end{array}$ & 78,4 & 76,9 \\
$\begin{array}{l}\text { Whole soybean } \\
\text { Fubá de milho } \\
\text { Corn grain ground }\end{array}$ & 91,1 & 96,6 \\
Caroço de algodão & 93,5 & 84,7 \\
Whole cottonseed & 80,3 & 80,3 \\
\hline
\end{tabular}


Tabela 5 - Estimativas dos coeficientes $\left(\beta_{1}\right)$ das equações de regressão entre os valores de NDT observados e preditos pela equação do NRC (2001)

Table 5 - Estimates of $\beta_{1}$ coefficients of the regression equations of the TDN values observed and predicted by NRC (2001) equations

\begin{tabular}{|c|c|c|}
\hline \multirow[t]{2}{*}{$\begin{array}{l}\text { Variável } \\
\text { Variable }\end{array}$} & \multicolumn{2}{|c|}{$\begin{array}{c}{ }^{1} \text { Coeficiente } \beta_{1} \\
\beta_{1} \text { coefficient }\end{array}$} \\
\hline & $\begin{array}{c}\text { Estimativa } \\
\text { Estimate }\end{array}$ & $\mathrm{r}^{2}(\%)$ \\
\hline $\begin{array}{l}\mathrm{NDTcj}^{2} \\
T D N c j^{2}\end{array}$ & $0,9164 \mathrm{~ns}$ & 70,12 \\
\hline $\begin{array}{l}\mathrm{NDTv}^{3} \\
T D N v^{3}\end{array}$ & $0,9004 \mathrm{~ns}$ & 87,66 \\
\hline $\begin{array}{l}\mathrm{NDTc}^{4} \\
T D N c^{4}\end{array}$ & $0,8873 \mathrm{~ns}$ & 75,35 \\
\hline $\begin{array}{l}{ }_{1} \text { Regress } \\
2 \text { Conjuntc } \\
3 \text { Alimentc } \\
{ }^{4} \text { Alimentc } \\
{ }^{1} \text { Regressi } \\
2 \text { Group of } \\
{ }^{3} \text { Roughag } \\
{ }^{4} \text { Concentr }\end{array}$ & teste t a $5 \%$ & \\
\hline
\end{tabular}

que as equações seriam adequadas para predizer o valor energético dos alimentos nas condições brasileiras. Contudo, observou-se que as equações do NRC (2001) não foram adequadas para estimar as frações digestíveis da FDN, do EE e dos CNF.

Entretanto, considerando que Costa (2002) verificou que as equações do NRC (2001) não foram eficientes para predizer as frações digestíveis dos nutrientes, recomenda-se mais pesquisas a respeito da utilização dessas equações, para que, a partir de um banco de dados maior, seja possível obter eficácia destas equações para predizer o valor energético dos alimentos nas condições brasileiras. As Figuras 1, 2 e 3 ilustram a dispersão dos pontos para a relação ideal $(\mathrm{Y}=\mathrm{X})$ entre os valores de NDT preditos pelo NRC e os observados.

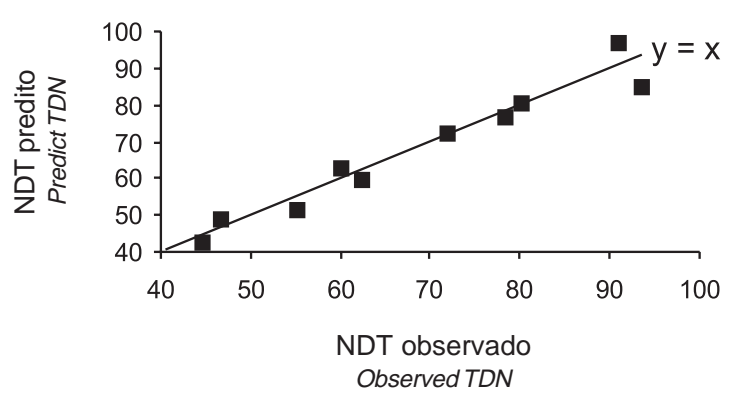

Figura 1 - Relação entre os valores de NDT preditos pelo NRC (2001) e observados, para o conjunto de alimentos.

Figure 1 - Relationship between TDN predicted by NRC (2001) and observed values, for the group of feeds.

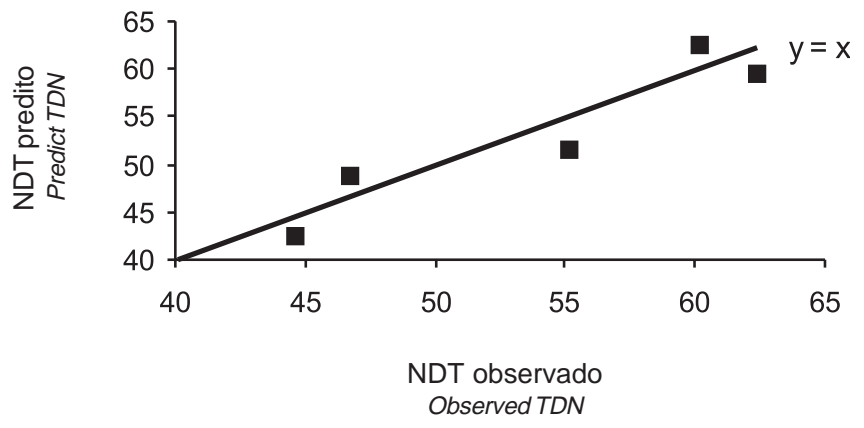

Figura 2 - Relação entre os valores de NDT preditos pelo NRC (2001) e observados, para os alimentos volumosos.

Figure 2 - Relationship between TDN predicted by NRC (2001) and observed values, for the roughage feeds.

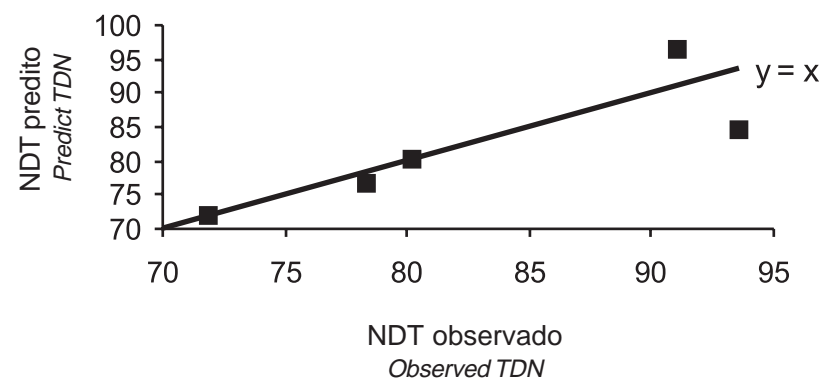

Figura 3 - Relação entre os valores de NDT preditos pelo NRC (2001) e observados para os alimentos concentrados.

Figure 3 - Relation among TDN predicted by NRC (2001) and observed values, for the concentrate feeds. 


\section{Conclusões}

As equações do NRC (2001) foram eficientes para determinação do valor energético dos alimentos estudados nas condições brasileiras.

\section{Literatura Citada}

COSTA, M.A.L. Desempenho de novilhos zebuínos e validação das equações do NRC (2001) para predizer o valor energético dos alimentos nas condições brasileiras. Viçosa, MG: Universidade Federal de Viçosa, 2002. 81p. Dissertação (Mestrado em Zootecnia) - Universidade Federal de Viçosa, 2002.

NATIONAL RESEARCH COUNCIL - NRC. Nutrient requeriments of dairy cattle. 6.rev.ed. Washinton, D.C.: 1989. $157 \mathrm{p}$.

NATIONAL RESEARCH COUNCIL - NRC. Nutrient requeriments of dairy cattle. 7.rev.ed. Washinton, D.C.: 2001. 381p.

ROCHA JR., V.R. Tabelas brasileiras de composição de alimentos, determinação e estimação do valor energético dos alimentos para ruminantes. Viçosa, MG: Universidade Federal de Viçosa, 2002. 252p. Tese (Doutorado em Zootecnia) - Universidade Federal de Viçosa, 2002.

ROCHA JR., V.R.; VALADARES FILHO, S.C.; BORGES, A.M. et al. Determinação do valor energético de alimentos para ruminantes pelo sistema de equações. Revista Brasileira de Zootecnia, v.32, n.2, p.473-479, 2003a.

ROCHA JR., V.R.; VALADARES FILHO, S.C.; BORGES, A.M. et al. Estmativa do valor energético e validação das equações propostas pelo NRC(2001). Revista Brasileira de Zootecnia, v.32, n.2, p.480-490, 2003 b.
SILVA, D.J. Análise de alimentos (métodos químicos e biológicos). Viçosa, MG: Universidade Federal de Viçosa, 1990. 165p.

VALADARES FILHO, S.C. Nutrição, avaliação de alimentos e tabelas de composição de alimentos para bovinos. In: REUNIÃO ANUAL DA SOCIEDADE BRASILEIRA DE ZOOTECNIA, 37., 2000, Viçosa, MG. Anais... Viçosa, MG: Sociedade Brasileira de Zootecnia, 2000. p.267-337.

Van SOEST, P.J.; ROBERTSON, J.B.; LEWIS, B.A. Methods for dietary fiber, neutral detergent fiber, and nonstarch polyssacarides in relation to animal nutrition. Journal Animal Science, v.74, n.10, p.3583-3597, 1991.

Van SOEST, J.P. Nutritional ecology of ruminant. 2.ed. Ithaca: Cornell University Press, 1994. 476p.

WATTIAUX, M.A. NRC de Gado de Leite 2001: O que mudou e como usá-lo. In: SIMPÓSIO DE NUTRIÇÃO E PRODUÇÃO DE GADO DE LEITE, 2001, Belo Horizonte. Anais... Belo Horizonte: 2001. p.83.

WEISS, W.P. Predicting energy values of feed. In. Symposium: prevailing concepts in energy utilization by ruminants. Journal Dairy Science, v.76, p.1802-1811, 1993.

WEISS, W.P. Energy prediction equations for ruminant feeds. In: CORNELL NUTRITION CONFERENCE FOR FEED MANUFACTURERS, 61., 1999, Ithaca. Proceedings... Ithaca: Cornell University, 1999. p.176-185.

Recebido em: 13/01/03 Aceito em: 15/12/04 